\title{
Preface: Multi-Disciplinary Arctic Research for Science and Society
}

\author{
Mioara Mandea • Tuija I. Pulkkinen
}

Published online: 9 September 2014

(C) Springer Science+Business Media Dordrecht 2014

The Northern and Southern polar regions have completely different dynamics due to their different geographical conditions. While the Antarctic is dominated by the large continent and ice sheet, the Arctic has much more variable conditions and is thus much more vulnerable to changes in the local conditions. While both domains need to be studied for building a comprehensive understanding of the global dynamics, the main aim of this Special Issue is to draw attention to the present state of the art of Arctic research and to involve a new generation of young scientists in this important topic. In terms of research, the focus has to be in interdisciplinary and circumpolar studies. As to development and governance, given the fragility of the human and natural ecology in the Arctic, decision making has to be based on analyses that consider the impact of the activities on the environment as well as on the Arctic societies.

Geoscientific research has been actively engaged in the Arctic for a long time, and the research community has widely recognized the need for multi-disciplinary efforts in this area. Global efforts have been focused on Arctic research through the International Polar Years, the first of which was held in 1882-1883. While the most recent International Polar Year of 2007-2008 improved the dynamics of research in the Arctic region, the results also underline the need for yet more efforts towards understanding the rapid variations in this area.

Recent developments in the Arctic concerning the climate, the environment, and human activities have opened up new perspectives in economic, social and geopolitical terms. Recent research results highlight the importance of the Arctic region as a tracer and

M. Mandea ( $\square)$

Earth Observation/Directorate for Strategy and Programmes, CNES-Centre National d'Etudes

Spatiales, Paris, France

e-mail: mioara.mandea@cnes.fr

T. I. Pulkkinen

Department of Radio Science and Engineering, Aalto University, Espoo, Finland

e-mail: tuija.pulkkinen@aalto.fi 
precursor for global change, while the latest environmental changes have boosted the utilization of the Arctic in a variety of economic activities. The Arctic is not only rich in natural resources, but is likely also to offer highly attractive new shipping routes in the decades to come. Tourism and health are other important developing areas.

Understanding the structure and the tectonic evolution of the high Arctic basins is crucial to future hydrocarbon exploration. Significant constraints need to be placed upon the development of the petroleum provinces. For a better description of the Arctic region, the available geophysical data need to be reconsidered, remodeled and re-interpreted. Also new datasets are crucial in these efforts: in addition to bathymetry, magnetic and gravity data, numerous other local or regional geophysical and geological data (including seismic, International Ocean Discovery Program and dredge data) together with global ones (satellite data and seismic tomography) can help us to better understand how basins formed and how continental masses were dispersed and accreted. Analysis of these comprehensive datasets requires new mathematical modeling tools on regional scales.

The cryosphere impacts the climate and the biological systems through physical and chemical processes. The recent reduction in sea ice and snow cover extent contributes via a reduced albedo to the regional amplification of climate change in the Arctic. A better understanding of key processes in the different components of the cryosphere (e.g., sea ice, snow, glaciers, ice sheets) and their interaction with the physical and biological environment is crucial. Atmospheric observations and models need to be coupled with the cryospheric, oceanic and environmental ones to gain a better understanding of mass and heat exchange between the regions and the complex coupled processes that drive the climate system.

In this special issue, we have collected a set of five review articles:

4D Arctic: a glimpse into the structure and evolution of the Arctic in the light of new geophysical maps, plate tectonics and tomographic models, by Gaina et al. (2014),

Survey of geomagnetic observations made in the northern sector of Russia and new methods for analyzing them, by Gvishiani et al. (2014),

Contemporary (1960-2012) evolution of the climate and surface mass balance of the Greenland ice sheet, by van Angelen et al. (2014),

Effects of Arctic sea ice decline on weather and climate, by Vihma (2104), and

Pattern variability in Arctic air temperature records, by Sutenau (2014),

that cover key, but not all, aspects of current Arctic research; they highlight the state of the art and the most recent developments in the field. The topics span the different disciplines, including observations, databases, modeling and interpretation of different phenomena. This collection of articles already underlines the interdisciplinary nature of the scientific research, and the need to further develop integrated and cross-disciplinary activities, both in observations and in modeling efforts. 